\title{
Predictors of diagnostic neuroimaging delays among adults presenting with symptoms suggestive of acute stroke in Ontario: a prospective cohort study
}

\author{
Kirsteen R. Burton MD, Moira K. Kapral MD, Shudong Li PhD, Jiming Fang PhD, \\ Alan R. Moody MBChB, Murray Krahn MD, Andreas Laupacis MD
}

\section{Abstract}

Background: Many studies have examined the timeliness of thrombolysis for acute ischemic stroke, but less is known about door-toimaging time. We conducted a prospective cohort study to assess the timing of neuroimaging among patients with suspected acute stroke in the province of Ontario, Canada, and to examine factors associated with delays in neuroimaging.

Methods: We included all patients 18 years and older with suspected acute stroke seen at hospitals with neuroimaging capacity within the Ontario Stroke Registry between Apr. 1, 2010, and Mar. 31, 2011. We used a hierarchical, multivariable Cox proportional hazards model to evaluate the association between patient and hospital factors and the likelihood of receiving timely neuroimaging ( $\leq 25 \mathrm{~min}$ ) after arrival in the emergency department.

Results: A total of 13250 patients presented to an emergency department with stroke-like symptoms during the study period. Of the 3984 who arrived within 4 hours after symptom onset, $1087(27.3 \%)$ had timely neuroimaging. The factors independently associated with an increased likelihood of timely neuroimaging were less time from symptom onset to presentation, more severe stroke, male sex, no history of stroke or transient ischemic attack, arrival to hospital from a setting other than home and presentation to a designated stroke centre or an urban hospital.

Interpretation: A minority of patients with stroke-like symptoms who presented within the 4-hour thrombolytic treatment window received timely neuroimaging. Neuroimaging delays were influenced by various patient and hospital factors, some of which are modifiable.

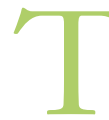
imely access to diagnostic neuroimaging is critical to the management of patients with suspected acute ischemic stroke. Thrombolysis with intravenous tissue plasminogen activator can reduce the risk of disability after stroke, but it must be administered within 4.5 hours after stroke onset and be preceded by brain imaging to confirm eligibility for the treatment. ${ }^{1}$ Stroke guidelines developed by the Brain Attack Coalition and the American Heart Association advise the completion of computed tomography (CT) within 25 minutes after arrival to the emergency department. ${ }^{1-3}$ The Canadian best practice recommendations for stroke care note that patients with suspected acute stroke or transient ischemic attack (TIA) should receive neuroimaging immediately. ${ }^{4}$

Numerous studies have examined the association between the time from symptom onset to arrival at the emergency department and the time from arrival to thrombolysis (frequently termed door-to-needle time). ${ }^{5-10}$ However, fewer studies have investigated the door-to-imaging time - one of the first windows in the management of patients with acute stroke - and there is little information on factors associated with delays in brain imaging. ${ }^{11}$

We undertook this study to assess the timing of neuroimaging (computed tomography $[\mathrm{CT}]$ or magnetic resonance imaging $[M R I]$ of the brain) in patients with symptoms suggestive of acute stroke who presented to hospitals with neuroimaging capacity in the province of Ontario, Canada. We determined the proportion of patients presenting within 4 hours after symptom onset (and thus were potentially eligible for

\section{Competing interests: None declared.}

Disclaimer: Kirsteen Burton is an Associate Editor for CMAJ Open and was not involved in the editorial decision-making process for this article.

This article has been peer reviewed.

Correspondence to: Kirsteen Burton, kirsteen.burton@utoronto.ca CMAJ Open 2016. DOI:10.9778/cmajo.20150110 
intravenous thrombolysis) who underwent timely neuroimaging. We also identified factors that predicted the likelihood of timely neuroimaging.

\section{Methods}

\section{Data sources}

The Ontario Stroke Registry (formerly known as the Registry of the Canadian Stroke Network) performs a biennial audit (the Ontario Stroke Audit) of patients with suspected stroke or TIA seen in an emergency department or admitted to hospital at any acute care institution in Ontario, excluding psychiatric hospitals. ${ }^{12}$ Chart abstraction is performed by specially trained neurology research personnel and includes abstraction of important timing variables, including time of stroke onset, time of arrival at the emergency department and time of first brain imaging. ${ }^{13,14}$ We used data from the audit performed in fiscal year 2010/11 and included only hospitals that had neuroimaging capacity, defined as having CT or MRI on site. We defined timely neuroimaging as the receipt of brain imaging within 25 minutes after arrival at the emergency department.

\section{Setting}

Hospitals included in the study were categorized as regional stroke centres, district stroke centres and nondesignated hospitals. Regional stroke centres use written stroke protocols for emergency services and within the emergency department. In addition, they have CT neuroimaging capability, clinicians with stroke expertise, neurosurgical and neurointerventional radiology facilities, and resources similar to those found in American comprehensive stroke centres. District stroke centres share the features of regional stroke centres, but they do not have on-site neurosurgical or neurointerventional radiology facilities and are similar to American primary stroke centres. Nondesignated hospitals do not fit the definition of a regional or district stroke centre but do have neuroimaging capability.

\section{Study population}

We included all patients 18 years and older with suspected acute stroke seen at hospitals with neuroimaging capacity between Apr. 1, 2010, and Mar. 31, 2011. If a patient presented more than once during the study period, data from only the first presentation were retained for analysis. We excluded patients who died before receipt of neuroimaging, those who were transferred from another hospital and patients for whom the exact time of stroke symptom onset was unknown. To limit our analyses to patients for whom rapid neuroimaging would guide decisions about eligibility for thrombolysis, we excluded patients who presented to hospital more than 4 hours after symptom onset.

\section{Statistical analysis}

We compared the characteristics of patients who received and did not receive neuroimaging using a $\chi^{2}$ test for categorical variables and a $t$ test for continuous variables. When the
National Institutes of Health Stroke Scale (NIHSS) score was missing, we used a formula to convert the Canadian Neurological Scale score to the NIHSS score. ${ }^{15} \mathrm{We}$ created a hierarchical Cox proportional hazards model to estimate the effect of time from presentation to neuroimaging and of demographic, medical history, patient presentation and hospital factors on the receipt of neuroimaging. To account for clustering by hospital type, we performed a random-effects multilevel (2-level) regression analysis, with patients being level 1 units and hospitals level 2 units in the model. We used the $\chi^{2}$ test for model hypothesis testing. We reported adjusted hazard ratios with $95 \%$ confidence intervals. Analyses were performed using SAS statistical software version 9.3. We considered $p$ values less than 0.05 to be statistically significant, and all $p$ values were based on 2-tailed tests.

\section{Results}

In 2010/11, 13250 patients were enrolled in the Ontario Stroke Registry. After we applied the exclusion criteria, our study cohort consisted of 3984 patients (Figure 1). The mean time from symptom onset to arrival at the emergency department was 1.49 (SD 0.89) hours. A total of 1087 patients $(27.3 \%)$ underwent timely neuroimaging after presentation (Table 1); $94.0 \%$ of the examinations were CT and $6.0 \%$ were MRI. The greatest proportion of patients who received timely neuroimaging were those who presented to the emergency department within 30 to 60 minutes after symptom onset. The

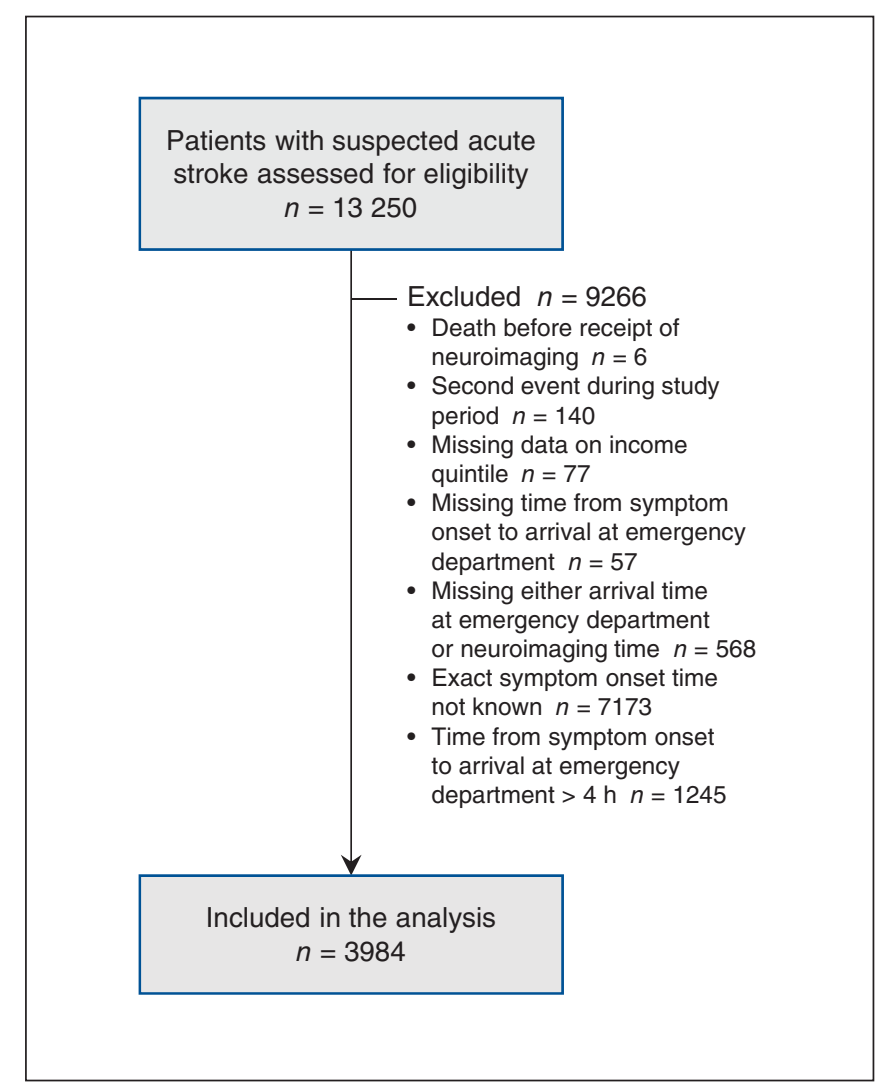

Figure 1: Selection of patients for the study cohort. 
Table 1 (part 1 of 2): Characteristics of patients with suspected acute stroke who arrived at emergency department within 4 hours after symptom onset and received timely neuroimaging ( $\leq 25 \mathrm{~min})$ or delayed neuroimaging

\begin{tabular}{|c|c|c|c|c|}
\hline Characteristic & $\begin{array}{c}\text { Total } \\
n=3984\end{array}$ & $\begin{array}{l}\text { Timely neuroimaging } \\
n=1087(\%)\end{array}$ & $\begin{array}{l}\text { Delayed neuroimaging } \\
\qquad n=2897(\%)\end{array}$ & $p$ value \\
\hline \multicolumn{5}{|l|}{ Patient } \\
\hline $\begin{array}{l}\text { Time from symptom onset to arrival at emergency } \\
\text { department, } h, \text { mean } \pm \text { SD }\end{array}$ & $1.49 \pm 0.89$ & $1.33 \pm 0.75$ & $1.55 \pm 0.93$ & $<0.001$ \\
\hline \multicolumn{5}{|l|}{ Time from symptom onset, $h$} \\
\hline$\leq 0.5$ & 280 & $64(22.9)$ & $216(77.1)$ & $<0.001$ \\
\hline$>0.5-1.0$ & 1245 & $399(32.0)$ & $846(68.0)$ & \\
\hline$>1.0-1.5$ & 939 & $273(29.1)$ & $666(70.9)$ & \\
\hline$>1.5-2.0$ & 580 & $169(29.1)$ & 411 (70.9) & \\
\hline$>2.0-3.0$ & 585 & $132(22.6)$ & $453(77.4)$ & \\
\hline$>3.0-4.0$ & 355 & $50(14.1)$ & 305 (85.9) & \\
\hline \multicolumn{5}{|l|}{ Age, yr } \\
\hline $18-44$ & 149 & $38(25.5)$ & $111(74.5)$ & 0.7 \\
\hline $45-64$ & 985 & $282(28.6)$ & $703(71.4)$ & \\
\hline $65-79$ & 1446 & $391(27.0)$ & $1055(73.0)$ & \\
\hline$\geq 80$ & 1404 & $376(26.8)$ & $1028(73.2)$ & \\
\hline \multicolumn{5}{|l|}{ NIHSS score } \\
\hline$\leq 4$ & 2352 & $383(16.3)$ & $1969(83.7)$ & $<0.001$ \\
\hline$>4$ & 1348 & $642(47.6)$ & $706(52.4)$ & \\
\hline Missing data & 284 & $62(21.8)$ & $222(78.2)$ & \\
\hline \multicolumn{5}{|l|}{ Sex } \\
\hline Female & 1947 & $484(24.9)$ & $1463(75.1)$ & $<0.001$ \\
\hline Male & 2037 & $603(29.6)$ & $1434(70.4)$ & \\
\hline \multicolumn{5}{|l|}{ Income quintile } \\
\hline 1 (lowest) & 785 & $202(25.7)$ & $583(74.3)$ & 0.8 \\
\hline 2 & 799 & $219(27.4)$ & $580(72.6)$ & \\
\hline 3 & 778 & $216(27.8)$ & $562(72.2)$ & \\
\hline 4 & 791 & $224(28.3)$ & $567(71.7)$ & \\
\hline 5 (highest) & 831 & $226(27.2)$ & $605(72.8)$ & \\
\hline \multicolumn{5}{|l|}{ Preferred language } \\
\hline English & 3509 & $926(26.4)$ & $2583(73.6)$ & 0.002 \\
\hline Other & 383 & $132(34.5)$ & $251(65.5)$ & \\
\hline UTD & 92 & $29(31.5)$ & $63(68.5)$ & \\
\hline \multicolumn{5}{|l|}{ Living independently before admission } \\
\hline No & 1117 & $278(24.9)$ & $839(75.1)$ & 0.03 \\
\hline Yes & 2867 & 809 (28.2) & $2058(71.8)$ & \\
\hline \multicolumn{5}{|l|}{ Medical history } \\
\hline \multicolumn{5}{|l|}{ Stroke, TIA or ICH } \\
\hline No & 2789 & $810(29.0)$ & $1979(71.0)$ & $<0.001$ \\
\hline Yes & 1195 & 277 (23.2) & $918(76.8)$ & \\
\hline \multicolumn{5}{|l|}{ Carotid revascularization } \\
\hline No & 3935 & $1073(27.3)$ & 2862 (72.7) & 0.8 \\
\hline Yes & 49 & $14(28.6)$ & $35(71.4)$ & \\
\hline
\end{tabular}




\section{OPEN}

Research

\begin{tabular}{|c|c|c|c|c|}
\hline Characteristic & $\begin{array}{c}\text { Total } \\
n=3984\end{array}$ & $\begin{array}{l}\text { Timely neuroimaging } \\
n=1087(\%)\end{array}$ & $\begin{array}{l}\text { Delayed neuroimaging } \\
\qquad n=2897(\%)\end{array}$ & $p$ value \\
\hline \multicolumn{5}{|l|}{ Diabetes mellitus } \\
\hline No & 3084 & $834(27.0)$ & $2250(73.0)$ & 0.5 \\
\hline Yes & 900 & $253(28.1)$ & $647(71.9)$ & \\
\hline \multicolumn{5}{|l|}{ Hypertension } \\
\hline No & 1332 & $326(24.5)$ & $1006(75.5)$ & 0.005 \\
\hline Yes & 2652 & $761(28.7)$ & $1891(71.3)$ & \\
\hline \multicolumn{5}{|l|}{ Hyperlipidemia } \\
\hline No & 2333 & $618(26.5)$ & $1715(73.5)$ & 0.2 \\
\hline Yes & 1651 & $469(28.4)$ & $1182(71.6)$ & \\
\hline \multicolumn{5}{|l|}{ Dementia } \\
\hline No & 3660 & $999(27.3)$ & $2661(72.7)$ & 0.9 \\
\hline Yes & 324 & $88(27.2)$ & $236(72.8)$ & \\
\hline \multicolumn{5}{|l|}{ Other cardiovascular disease } \\
\hline No & 2831 & $732(25.9)$ & $2099(74.1)$ & 0.002 \\
\hline Yes & 1153 & $355(30.8)$ & 798 (69.2) & \\
\hline \multicolumn{5}{|l|}{ Presentation } \\
\hline \multicolumn{5}{|l|}{ During business hours } \\
\hline No & 2552 & $714(28.0)$ & $1838(72.0)$ & 0.2 \\
\hline Yes & 1432 & $373(26.0)$ & $1059(74.0)$ & \\
\hline \multicolumn{5}{|l|}{ Arrived to hospital from } \\
\hline Home & 3539 & $972(27.5)$ & $2567(72.5)$ & 0.02 \\
\hline $\begin{array}{l}\text { Nursing, retirement home or complex } \\
\text { continuing care }\end{array}$ & 327 & $95(29.1)$ & $232(70.9)$ & \\
\hline Other & 14 & $\leq 5(35.7)$ & $9(64.3)$ & \\
\hline Missing or UTD & 104 & $15(14.4)$ & $89(85.6)$ & \\
\hline \multicolumn{5}{|l|}{ Hospital } \\
\hline \multicolumn{5}{|l|}{ Type } \\
\hline Regional stroke centre & 1798 & $523(29.1)$ & $1275(70.9)$ & $<0.001$ \\
\hline District stroke centre & 1404 & $521(37.1)$ & $883(62.9)$ & \\
\hline Not a stroke centre & 782 & $43(5.5)$ & $739(94.5)$ & \\
\hline \multicolumn{5}{|l|}{ Location } \\
\hline Rural (population < 10 000) & 3785 & $1081(28.6)$ & $2704(71.4)$ & $<0.001$ \\
\hline Urban & 199 & $6(3.0)$ & $193(97.0)$ & \\
\hline \multicolumn{5}{|l|}{ Annual stroke volume } \\
\hline High (> 200) & 3341 & $1005(30.1)$ & $2336(69.9)$ & $<0.001$ \\
\hline Medium (101-200) & 375 & $65(17.3)$ & $310(82.7)$ & \\
\hline $\operatorname{Low}(\leq 100)$ & 268 & $17(6.3)$ & $251(93.7)$ & \\
\hline
\end{tabular}

median time from presentation to neuroimaging was 0.80 (interquartile range 0.38-2.30) hours.

In the univariable analysis, many factors were associated with timely neuroimaging (Table 1). The proportion of patients who received timely neuroimaging was higher at the designated stroke centres than at the nondesignated hospitals $(29.1 \%$ at regional and $37.1 \%$ at district stroke centres v. $5.5 \%$ at nondesignated hospitals). In the multivariable analy- 
sis, the factors independently associated with an increased likelihood of timely neuroimaging were less time from symptom onset to presentation, more severe stroke symptoms (NIHSS score > 4), male sex, no history of stroke or TIA, arrival to hospital from a setting other than home and presentation to a designated district or regional stroke centre or to an urban hospital (Table 2).

\section{Interpretation}

Our study showed that timely neuroimaging was performed in less than one-third of patients with suspected acute stroke who presented to an emergency department within 4 hours after symptom onset (i.e., a time when neuroimaging could have reasonably been performed within the 4.5-hour thrombolytic treatment window). These results suggest that the management of some patients with acute ischemic stroke is suboptimal and that otherwise eligible patients are not receiving thrombolytic or endovascular therapy.

Few prior studies examined neuroimaging rates among patients with suspected acute stroke. A study from the United States found that $41.7 \%$ of patients with suspected stroke underwent neuroimaging within 25 minutes after hospital arrival; however, the study sample was limited to patients whose time from symptom onset to emergency department arrival was 2 hours or less. ${ }^{16}$ This timeframe reflected the previous recommendation of a 3-hour window for thrombolysis. ${ }^{16}$ A number of other studies also examined neuroimaging rates among patients with acute ischemic stroke or patients who presented with stroke-like symptoms. ${ }^{15-18}$ However, they restricted the study samples to patients who ultimately received thrombolytic therapy, ${ }^{17,18}$ or they estimated rates of imaging within 25 minutes among patients who presented either within 2 or within 4.5 hours after symptom onset. ${ }^{16,19,20}$

We identified a number of factors independently associated with neuroimaging delays. Patients who presented to a rural hospital with imaging capacity were less likely than those presenting to urban hospitals to receive timely neuroimaging. This finding is consistent with previous studies whose findings suggested that patients seen at rural centres are less likely to receive neuroimaging, ${ }^{21}$ to use emergency medical services ${ }^{22}$ or to receive intravenous thrombolysis ${ }^{23}$ and that hospitals with greater volumes of stroke patients have increased rates of neuroimaging. ${ }^{24}$ Although we found that patients who presented to a designated stroke centre were more likely to receive timely neuroimaging than those seen at other centres, the proportion of patients who received timely neuroimaging was still surprisingly low.

Patients who presented with less severe stroke symptoms were more likely than those with more severe symptoms to experience a neuroimaging delay. These findings are consistent with other studies showing that patients with an NIHSS score of 4 or less had an increased door-to-needle time ${ }^{7}$ and that patients with more severe stroke symptoms at presentation were more likely to receive neuroimaging within $25 \mathrm{~min}$ utes. ${ }^{16}$ Possible explanations for these findings include a lower
Table 2: Factors associated with timely receipt of neuroimaging among patients with suspected acute stroke who presented within $\mathbf{4}$ hours after symptom onset

\begin{tabular}{|c|c|}
\hline Factor & $\begin{array}{c}\text { Hazard ratio } \\
(95 \% \mathrm{Cl})\end{array}$ \\
\hline
\end{tabular}

Time from symptom onset to arrival at hospital, $\mathrm{h}$

(v. $\leq 0.5 \mathrm{~h})$

\begin{tabular}{|cc|}
\hline$>0.5-1.0$ & $1.59(1.21-2.08)$ \\
\hline$>1.0-1.5$ & $1.55(1.18-2.05)$ \\
\hline$>1.5-2.0$ & $1.37(1.02-1.84)$ \\
\hline$>2.0-3.0$ & $1.31(0.96-1.77)$ \\
\hline$>3.0-4.0$ & $0.81(0.56-1.19)$ \\
\hline Age group, yr (v. $\geq 80)$ & \\
\hline $18-44$ & $1.13(0.79-1.61)$ \\
\hline $45-64$ & $1.16(0.98-1.39)$ \\
\hline $65-79$ & $1.06(0.91-1.24)$ \\
\hline
\end{tabular}

NIHSS score ( $v . \leq 4)$

$\mathrm{NIHSS}>4 \quad 3.54(3.09-4.05)$

Missing $2.21(1.61-3.05)$

$\begin{array}{ll}\text { Female sex } & 0.76(0.67-0.86)\end{array}$

Income quintile (v. 1, lowest)

\begin{tabular}{ll}
2 & $1.10(0.91-1.34)$ \\
3 & $1.19(0.97-1.45)$ \\
4 & $1.15(0.94-1.40)$ \\
5 (highest) & $1.18(0.97-1.44)$ \\
\hline Preferred language (v. English) &
\end{tabular}

Preferred language (v. English)

$\begin{array}{ll}\text { Other } & 1.06(0.86-1.30) \\ \text { UTD } & 0.82(0.55-1.22)\end{array}$

Not living independently before admission $\quad 0.85(0.72-1.01)$

Medical history

Stroke, TIA, ICH $\quad 0.78(0.67-0.89)$

Carotid therapy $0.66(0.38-1.13)$

Diabetes mellitus $\quad 0.96(0.82-1.10)$

Hypertension $1.11(0.95-1.28)$

Hyperlipidemia $\quad 1.01(0.88-1.15)$

Dementia $0.95(0.74-1.21)$

Other cardiovascular disease $\quad 1.08(0.94-1.24)$

Presentation

Outside business hours $\quad 1.07(0.94-1.22)$

Arrived to hospital from (v. from home)

Nursing, retirement home or complex

continuing care

Other $1.90(0.77-4.67)$

Missing or UTD

$0.44(0.24-0.81)$

Hospital

Type (v. nondesignated hospital)

\begin{tabular}{lc} 
Regional stroke centre & $5.60(2.70-11.62)$ \\
\hline District stroke centre & $6.78(3.66-12.56)$ \\
Rural location (v. urban) & $0.08(0.02-0.36)$ \\
\hline Annual stroke volume (v. high) & \\
\hline Medium (101-200) & $1.06(0.54-2.05)$ \\
\hline Low $(\leq 00)$ & $2.73(1.00-7.47)$
\end{tabular}

SS = National

Note: $\mathrm{Cl}=$ confidence interval, $\mathrm{ICH}=$ intracranial hemorrhage, $\mathrm{NIHSS}=$ National
Institutes of Health Stroke Scale, ref = reference category, TIA = transient

ischemic attack, UTD = unable to determine. 
diagnostic suspicion for stroke when patient symptoms are milder or an assumption that patients with milder symptoms are not candidates for thrombolytic therapy. Patients who had a shorter time from symptom onset to emergency department arrival received neuroimaging faster than patients with longer times to arrival. This is in contrast to earlier studies that reported a "neuroimaging paradox," whereby patients who presented earlier experienced delayed neuroimaging or delayed thrombolytic therapy. $5,7,10,16,25-27$

In our study, women were less likely than men to receive timely neuroimaging, which is conistent with findings in 4 other studies, 1 of which also found a delay in door-todoctor time. ${ }^{16,28-30}$ Age and socioeconomic status were not factors influencing neuroimaging time in our study, which is in contrast to a study conducted in the United States. ${ }^{13}$ Ontario's universal public coverage of hospital care may account for this difference.

Our results suggest an urgent need to focus on decreasing the door-to-imaging time among patients who present with suspected acute stroke in Ontario. This would be in keeping with recent recommendations to shift the focus of ischemic stroke policy from extending the window for thrombolytic therapy to providing more rapid treatment. ${ }^{31}$ Decreasing the door-to-imaging time should be part of an overall qualityimprovement initiative, such as that suggested by Sauser and associates, ${ }^{17}$ wherein time to neuroimaging was 1 of 10 evidence-based strategies to increase the likelihood of timely reperfusion. Recent studies have reported substantial improvements in door-to-imaging performance with the adoption of these initiatives. ${ }^{17,32,33}$ Of note, Ontario has a regional system of stroke care that already endorses many interventions designed to facilitate timely reperfusion, including pre-notification of a suspected stroke by emergency medical services to the receiving hospital, formation of acute stroke teams, stroke-specific medical order sets, and encouragement of direct transfer of patients from the emergency department triage area to the imaging scanner where possible. ${ }^{34}$

\section{Strengths and limitations}

The principal strengths of our study are the large populationbased sample, the complete and high-quality data set, statistical analyses accounting for the hierarchical nature of the data, and the fact that patients were managed after the publication of recent stroke guidelines. ${ }^{35}$

The primary limitation is, as with any observational study, the potential influence of confounding variables. The Ontario Stroke Audit did not collect information about some variables that may affect time to neuroimaging, such as patient preferences, the effect of stroke on the ability to communicate, existence of advanced care directives and emergency department overcrowding.

\section{Conclusion}

We found that only a minority of patients with suspected acute stroke who arrived at hospital within the 4-hour thrombolytic treatment window received timely neuroimaging in
Ontario hospitals with neuroimaging capability in 2010/11. Quality-improvement initiatives are urgently needed to address this issue, as a means of increasing the number of patients with acute stroke who receive appropriate revascularization therapy.

\section{References}

1. Jauch EC, Saver JL, Adams HP, et al.; American Heart Association Stroke Council; Council on Cardiovascular Nursing; Council on Peripheral Vascular Disease; Council on Clinical Cardiology. Guidelines for the early management of patients with acute ischemic stroke: a guideline for healthcare professionals from the American Heart Association/American Stroke Association. Stroke 2013;44:870-947.

2. Saver JL. Time is brain - quantified. Stroke 2006;37:263-6.

3. Alberts MJ, Latchaw RE, Selman WR, et al. Recommendations for comprehensive stroke centers: a consensus statement from the Brain Attack Coalition. Stroke 2005;36:1597-616.

4. Casaubon LK, Boulanger JM; Hyperacute and Acute Stroke Writing Group. Hyperacute stroke care 2015 update. In: Lindsay MP, Gubitz G, Bayley M, et al., editors; Canadian Stroke Best Practices and Advisory Committee. Canadian Stroke Best Practice Recommendations. Ottawa: Heart and Stroke Foundation; 2015. Available: www.strokebestpractices.ca/index.php/hyperacute-stroke -management/ (accessed May 2016).

5. Strbian D, Michel P, Ringleb P, et al. Relationship between onset-to-door time and door-to-thrombolysis time: a pooled analysis of 10 dedicated stroke centers. Stroke 2013;44:2808-13.

6. Bray BD, Campbell J, Cloud GC, et al. Bigger, faster? Associations between hospital thrombolysis volume and speed of thrombolysis administration in acute ischemic stroke. Stroke 2013;44:3129-35.

7. Ferrari J, Knoflach M, Seyfang L, et al.; Austrian Stroke Unit Registry Collaborators. Differences in process management and in-hospital delays in treatment with IV thrombolysis. PLoS One 2013;8:e75378.

8. Fonarow GC, Smith EE, Saver JL, et al. Timeliness of tissue-type plasminogen activator therapy in acute ischemic stroke: patient characteristics, hospital factors, and outcomes associated with door-to-needle times within 60 minutes. Circulation 2011;123:750-8.

9. Köhrmann M, Schellinger PD, Breuer L, et al. Avoiding in hospital delays and eliminating the three-hour effect in thrombolysis for stroke. Int 7 Stroke 2011;6:493-7.

10. Saver JL, Smith EE, Fonarow GC, et al.; GWTG-Stroke Steering Committee and Investigators. The "golden hour" and acute brain ischemia: presenting features and lytic therapy in $>30,000$ patients arriving within 60 minutes of stroke onset. Stroke 2010;41:1431-9.

11. Sauser K, Burke JF, Levine DA, et al. Time to brain imaging in acute stroke is improving: secondary analysis of the INSTINCT trial. Stroke 2014;45:287-9.

12. Ontario Stroke Registry: acute stroke databases. Toronto: Institute for Clinical Evaluative Sciences. Available: www.ices.on.ca/Research/Research-programs/ Cardiovascular/Ontario-Stroke-Registry/OSR-Acute-Stroke-Databases (accessed 2015 Oct. 4).

13. Hall R, Khan F, O'Callaghan C, et al. Ontario stroke evaluation report 2014: on target for stroke prevention and care. Toronto: Institute for Clinical Evaluative Sciences; 2014. Available: www.ices.on.ca/Publications/Atlases-and-Reports/2014/ Ontario-Stroke-Evaluation-Report-2014 (accessed May 2016).

14. Ontario Stroke Registry. Toronto: Institute for Clinical Evaluative Sciences. Available: www.ices.on.ca/Research/Research-programs/Cardiovascular/ Ontario-Stroke-Registry (accessed 2015 Oct. 9).

15. Nilanont Y, Komoltri C, Saposnik G, et al. The Canadian Neurological Scale and the NIHSS: development and validation of a simple conversion model. Cerebrovasc Dis 2010;30:120-6.

16. Kelly AG, Hellkamp AS, Olson D, et al. Predictors of rapid brain imaging in acute stroke: analysis of the Get With the Guidelines-Stroke program. Stroke 2012;43:1279-84.

17. Sauser K, Levine DA, Nickles AV, et al. Hospital variation in thrombolysis times among patients with acute ischemic stroke: the contributions of door-toimaging time and imaging-to-needle time. 7AMA Neurol 2014;71:1155-61.

18. Sauser K, Burke JF, Levine DA, et al. Time to brain imaging in acute stroke is improving: secondary analysis of the INSTINCT trial. Stroke 2014;45:287-9.

19. Fonarow GC, Zhao X, Smith EE, et al. Door-to-needle times for tissue plasminogen activator administration and clinical outcomes in acute ischemic stroke before and after a quality improvement initiative. $7 A M A$ 2014;311:1632-40.

20. Haršány M, Kadlecová P, Svigelj V, et al. Factors influencing door-to-imaging time: analysis of the safe implementation of treatments in Stroke-EAST registry. 7 Stroke Cerebrovasc Dis 2014;23:2122-9.

21. Hodgson C. Emergency management of acute ischemic stroke in Canadian hospitals. CMA7 1998;159(Suppl):S15-8.

22. Ekundayo OJ, Saver JL, Fonarow GC, et al. Patterns of emergency medical services use and its association with timely stroke treatment: findings from Get 
With the Guidelines-Stroke. Circ Cardiovasc Qual Outcomes 2013;6:262-9.

23. Kozera G, Chwojnicki K, Gójska-Grymajło A, et al. Pre-hospital delays and intravenous thrombolysis in urban and rural areas. Acta Neurol Scand 2012;126:171-7.

24. Saposnik G, Baibergenova A, O'donnell M, et al. Hospital volume and stroke outcome: Does it matter? Neurology 2007;69:1142-51.

25. Mikulík R, Kadlecová P, Czlonkowska A, et al.; Safe Implementation of Treatments in Stroke-East Registry (SITS-EAST) Investigators. Factors influencing in-hospital delay in treatment with intravenous thrombolysis. Stroke 2012;43: 1578-83.

26. Tekle WG, Chaudhry SA, Hassan AE, et al. Utilization of intravenous thrombolysis in 3-4.5 hours: analysis of the Minnesota Stroke Registry. Cerebrovasc Dis 2012;34:400-5.

27. Romano JG, Muller N, Merino JG, et al. In-hospital delays to stroke thrombolysis: paradoxical effect of early arrival. Neurol Res 2007;29:664-6.

28. Gargano JW, Wehner S, Reeves MJ. Do presenting symptoms explain sex differences in emergency department delays among patients with acute stroke? Stroke 2009;40:1114-20.

29. Di Carlo A, Lamassa M, Baldereschi M, et al. Sex differences in the clinical presentation, resource use, and 3-month outcome of acute stroke in Europe: data from a multicenter multinational hospital-based registry. Stroke 2003;34:1114-9.

30. Yu RF, San Jose MC, Manzanilla BM, et al. Sources and reasons for delays in the care of acute stroke patients. 7 Neurol Sci 2002;199:49-54.

31. Hill MD, Coutts SB. Alteplase in acute ischaemic stroke: the need for speed. Lancet 2014;384:1904-6.

32. Baker LC, Atlas SW, Afendulis CC. Expanded use of imaging technology and the challenge of measuring value. Health Aff (Millwood) 2008;27:1467-78.

33. Ruff IM, Ali SF, Goldstein JN, et al. Improving door-to-needle times: a single center validation of the target stroke hypothesis. Stroke 2014:45:504-8.

34. Ontario's regional stroke networks (Ontario Stroke System). Toronto: Ontario Stroke Network. Available: ontariostrokenetwork.ca/about-the-osn/ontario -stroke-system-oss/ (accessed 2015 Jun. 16).
35. Smaha LA; American Heart Association. The American Heart Association Get With The Guidelines program. Am Heart 72004;148:S46-8.

Affiliations: Institute of Health Policy, Management and Evaluation (Burton, Kapral, Krahn, Laupacis), University of Toronto; Departments of Medical Imaging (Burton, Moody) and Medicine (Kapral, Krahn, Laupacis), University of Toronto; Institute for Clinical Evaluative Sciences (Kapral, Li, Fang); Institute of Medical Sciences (Moody), University of Toronto; Toronto Health Economics and Technology Assessment Collaborative (Krahn), University of Toronto; Li Ka Shing Knowledge Institute (Laupacis), St. Michael's Hospital, Toronto, Ont.

Contributors: All of the authors contributed to the study concept and design, and the acquisition, analysis and interpretation of data. Kirsteen Burton drafted the manuscript. All of the authors revised it critically for important intellectual content, approved the final version to be published and agreed to act as guarantors of the work.

Supplemental information: For reviewer comments and the original submission of this manuscript, please see www.cmajopen.ca/content/4/2/ E331/suppl/DC1

Disclaimer: This study was supported by the Institute for Clinical Evaluative Sciences (ICES), which is funded by an annual grant from the Ontario Ministry of Health and Long-Term Care (MOHLTC). The opinions, results and conclusions reported in this article are those of the authors and are independent from the funding sources. No endorsement by ICES or the Ontario MOHLTC is intended or should be inferred. 